IFN Working Paper No. 747, 2008

\title{
Open Versus Closed Platforms
}

Joacim Tåg 


\title{
Open Versus Closed Platforms
}

\author{
Joacim Tåg *†
}

August 28, 2008

\begin{abstract}
This paper studies an industry where firms can choose to provide open or closed platforms. Open, as opposed to closed, platforms are extendable so that third-party producers can develop extensions for them. Building on a two-sided market model, I show that firms might prefer to commit to keeping their platforms closed despite the fact that opening the platform is costless and open platforms are more valuable to consumers. The reason is that opening the platform may lead to intensified competition for consumers.
\end{abstract}

Keywords: Platforms; Software; Two-sided markets.

JEL Codes: D40; D42; D43; L10; L12; L13; L14.

* Swedish School of Economics and Business Administration, FDPE and HECER (Arkadiankatu 7, 00101 Helsinki, Finland) and the Research Institute of Industrial Economics (IFN) (P.O. Box 55665, SE-102 15 Stockholm, Sweden). E-mail: joacim.tag@ifn.se.

$\dagger$ I am greatful for financial support from the Finnish Doctoral Programme in Economics and the Research and Training Foundation of TeliaSonera Finland Oyj. I thank Jay Pil Choi, Charlotta Grönqvist, Klaus Kultti, Andras Niedermayer, Lars Sørgard, Rune Stenbacka and participants at the FDPE Microeconomics and Industrial Organization Workshop in Helsinki and the 6th ZEW Conference on the Economics of ICT in Mannheim for insightful comments. 


\section{Introduction}

"Tech firms today are caught in a bind, between being open (to attract a community of developers) and closed (to ensure high standards and maintain their traditional business models)."

- The Economist $(2008)^{1}$

Why are some platforms open to third-party development while others are closed? As the quote above highlights, it may be a trade-off between attracting a developer community (that raises the value of the platform) and ensuring high standards. In this paper, however, I take a two-sided market approach and highlight that being open and attracting third-party developers may also lead to intensified competition between platforms for consumers. Because of this, firms might prefer to commit to keeping their platforms closed despite the fact that opening the platform is costless and raises the value of the platform to consumers.

The choice between supplying an open versus a closed platform is relevant in a number of markets. For example, operating systems for modern personal computers are prime examples of open platforms. Apple's OS X, Microsoft's Windows Vista and various versions of Linux all allow for, and encourage, application development. The same holds for video game consoles. As of 2008, the three large consoles on the market (the Xbox360, the Playstation 3 and the Wii) are all sold as open platforms with third-parties developing games for the consoles. But there also exists a sea of cheaper closed consoles that come with one or several pre-installed games (such as Sudoku or Tetris).

In some markets the same firm might provide both open and closed platforms. For example, high-end phones usually already have an operating system installed that allows for third-party applications. ${ }^{2}$ The Nokia N95 comes with the S60 software that permits users to install software from third-party application developers. Cheaper mobile phones, such as the Nokia 1600, are often closed and no applications can be installed. Interestingly, when Apple entered the mobile phone market in June 2007 with the iPhone, they entered with a closed platform. Native third-party application development was impossible for the phone, thereby upsetting developers that had become used to open high-end phones. Apple, however, responded by releasing a software development kit for the iPhone in June 2008, which implied that third-party development is now possible. $^{3}$

In some markets, platforms shift from open to closed over time. In enterprise software, for example, there seems to have been a shift towards closed platforms. The following account is from Arora and Bokhari (2007): "In enterprise software, for instance, SAP offers a closed product (an integrated suite, to use the industry term), with various application modules designed to work with the basic SAP enterprise resource planning (ERP) platform. Instead, until recently, users could opt for an Oracle database platform, using applications from Peoplesoft for

\footnotetext{
${ }^{1}$ The Economist, "Who holds the key?", Aug 15th 2008 from Economist.com.

${ }^{2} \mathrm{~A}$ mobile phone can be seen as a platform in a two-sided market since the operating system that it runs on it allows users of the phone and third-party developers that write applications for the phone to interact.

${ }^{3}$ http://www.apple.com/pr/library/2008/03/06iphone.html. Accessed August 2008.
} 
human resources, JD Edwards for financial management, Siebel for customer relationship management and so on. In the last couple of years, all of these companies were acquired by Oracle, and it is likely that in the future, it will offer an integrated suite as well, so that we might see only competing closed systems in this market."

I am naturally not the first to analyze the choice between supplying an open versus a closed platform. ${ }^{4}$ Kende (1998) compares the profitability of open versus closed systems. He departs from the literature on aftermarkets. ${ }^{5}$ A firm can sell an open platform for a high price and encourage competition and cheap provision of extensions by third-parties in an aftermarket when consumers have already bought the platform. Alternatively, the firm could sell a cheap closed platform and itself provide extensions at a monopoly price in the aftermarket. Kende (1998) shows that an open system is more profitable when demand for the system is more elastic, secondary component variety is valued more highly and when the main component has a large share of consumers' budget.

Matutes and Regibeau (1988) study configurations with mix and matching of components. ${ }^{6}$ Compatibility (open platforms) allows consumers to mix and match components from two competing firms. Incompatibility (closed platforms) forces consumers to buy both components from the same firm. The authors show that industries should tend towards compatibility, because compatibility shifts the industry demand curve upwards and relaxes price competition.

Church and Gandal (2000) introduce a taste for variety in secondary components in their study of hardware and software systems. Closing the system implies integration into the secondary component and enforcing incompatibility with the other component. The profitability of closing the system depends on a trade-off between profits from selling software produced in-house, and profit increases from selling more hardware when there is a larger variety of software provided by third-parties.

Arora and Bokhari (2007) build a dynamic model of open versus closed systems. They emphasize that firms may differ in their costs of producing different components. Open firms can specialize in producing one component while closed firms cannot and must produce both components. In the long run, the trade-off is between diseconomies of scope (in favor of open systems) and costs of transacting across firm boundaries (in favor of closed systems).

On a theoretical basis, and in contrast to the above mentioned papers, I build on the existing literature on two-sided markets. ${ }^{7}$ I start from a stylized two-sided market model that builds on Armstrong (2006) and I endogenize the choice of operating in a one-sided (closed) or two-sided (open) market. Much of the early literature on two-sided markets focuses on solving the problem of how much to charge each side. Related to comparing one and two-sided markets, there has been some work on the difference between operating as a merchant

\footnotetext{
${ }^{4}$ The concept of open and closed platforms has been interpreted in different ways in the literature. Schiff (2003) analyzes open and closed systems of two-sided networks, referring to compatibility between two platforms (e.g. if applications developed for one platform work with the other). Hagiu (2007b) analyzes open versus proprietary platforms, where an open platform indicates that prices are zero on both sides.

${ }^{5}$ See also Shapiro (1995) and Borenstein and MacKie-Mason (2000).

${ }^{6}$ See also Economides (1989).

${ }^{7}$ See, for example, Rochet and Tirole (2003), Caillaud and Jullien (2003), Rochet and Tirole (2006), Hagiu (2006), Choi (2006) and Armstrong (2006).
} 
versus operating as a platform. According to Hagiu (2007a), the main difference is that a merchant takes full possession of the content, whereas a platform leaves control over the sale to sellers and simply intermediates the transaction. There is also related work on exclusivity in two-sided markets by Hagiu and Lee (2007) and Lee (2007). In their model, a content provider joins one or both platforms depending on whether the content is exclusive or not. In contrast, I compare the platforms' choice between allowing third-parties or not. ${ }^{8}$

In taking the two-sided market route, my approach is different from that of Kende (1998) in that I assume away the central hold-up problem in the aftermarket literature. Instead, I focus on the ability of firms to charge (or subsidize) third-parties for the right to develop applications for the platform. Adding this dimension, the firms can directly profit from selling rights to develop for the platform. They also have the ability to subsidize developers to encourage application development. I mainly differ from the components versus systems approach in Matutes and Regibeau (1988), Church and Gandal (2000) and Arora and Bokhari (2007) by analyzing atomistic producers of secondary components instead of two (or more) components produced by the same (or different) firms. I place heavy emphasis on the existence of cross-group externalities between consumers and application developers. Further, I completely "black box" the pricing decision of application developers. My approach has the advantage of emphasizing cross-group externalities and platform pricing to internalize them. The drawback is that I assume away potentially important strategic interactions between the price of the platform and the price of applications set by application developers.

\section{The Model}

I study a two-stage duopoly model of a two-sided market where software platforms connect consumers with third-party application providers. There are two platforms, $k \in\{1,2\}$, each with the same intrinsic value $v$. The value of any applications developed in-house by the platform is also included in $v$. The number of these applications is exogenous and independent of the platform being open or closed. For example, the same basic set of applications (such as a calendar, a phone book, an alarm clock, a simple game) bundled with high-end open phones is also often available on closed low-end phones. When Apple introduced the closed iPhone, the set of built-in applications resembled the basic set of applications bundled with other competing high-end phones.

The platforms can be open, in which case they connect consumers with application developers, or they can be closed and simply sell the platform of value $v$ to consumers. If open, platforms can set a fee (or subsidy) for the right to develop an application. Finally, the costs for opening the platform are zero. Fixed costs are sunk and marginal costs zero. Consumers only buy one platform, but application developers may develop for any or both of the open platforms.

\footnotetext{
${ }^{8}$ One of the results in Hagiu and Lee (2007) is that platforms might want to give up control rights over pricing content in order to relax competition. This result is perhaps most closely related to this paper as platform here might want to give up all gains (from consumers and/or from third-parties) in order to relax competition.
} 


\subsection{Consumers}

Consumers are uniformly distributed on the unit interval with the platforms located at the endpoints of the interval. The intrinsic value of the platforms, $v$, is sufficiently large for the market to be completely covered. ${ }^{9}$

In the eyes of consumers, the platforms only differ in price and the number of applications available. A consumer denoted by $i$ receives utility

$$
u_{i 1}=\left(v-t x_{i}\right)+b n_{a 1}-p_{1},
$$

if buying platform 1 and utility

$$
u_{i 2}=\left(v-t\left(1-x_{i}\right)\right)+b n_{a 2}-p_{2},
$$

if buying platform 2. The number of applications available at platforms 1 and 2 are given by $n_{a 1}$ and $n_{a 2}$. The parameter $b>0$ measures the additional value of the platform for each available third-party application. Platform prices are $p_{1}$ and $p_{2}$. The transportation cost parameter, $t$, measures the intensity of competition.

\subsection{Application Developers}

The application developers are independent monopolists. They are treated as atomistic and are uniformly distributed on the unit interval, $y \in[0,1]$.

Developers are heterogeneous in terms of fixed costs for coming up with a business idea, setting up shop and developing an application. An application developer indexed by $y_{j}$ has fixed costs equal to $f y_{j}$ for developing an application.

Each application developer is able to extract an expected profit of $a>0$ from each consumer purchasing the platform. These profits are generated from sources such as selling advertising space or increased sales from complementary products.

Application developers are allowed to multi-home. This means that they may develop applications for both platforms. If both platforms are open, application developers make the decision to develop for one platform independently of the decision to develop for the other platform. Thus, there is no direct competition between the firms for developers. A firm can attract more developers by either reducing the price of the platform, thereby selling to more consumers, or by reducing the fee or increasing the subsidy for application development. Application developers must pay the fixed development cost twice if they wish to supply an application for both platforms.

Conditional on the number of consumers at each platform, an application developer $j$ has profits equal to

$$
\pi_{j k}=a n_{c k}-f y_{j}-s_{k}
$$

\footnotetext{
${ }^{9}$ The condition needed when both platforms are closed is $v>\frac{3 t}{2}$. When both firms provide open platforms the condition is $v>\frac{6 f t-a^{2}-3 a b}{4 f}$. When one platform is closed and the other is open, the conditions are $a b f(9 t-4 v)>a^{3} b+f\left(6 f t(3 t-2 v)+b^{2} v\right)+a^{2}\left(b^{2}+f(v-3 t)\right)$ and $f\left(b^{2}(3 t-v)+6 f t(2 v-3 t)\right)>a\left(a^{2} b+2 a b^{2}+b^{3}-3 a f t-12 b f t+(a+4 b) f v\right)$.
} 


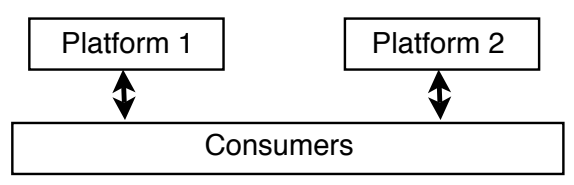

Open-Closed

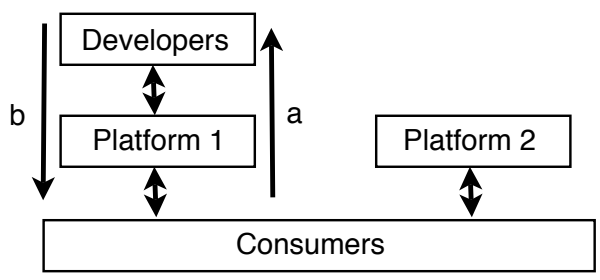

b

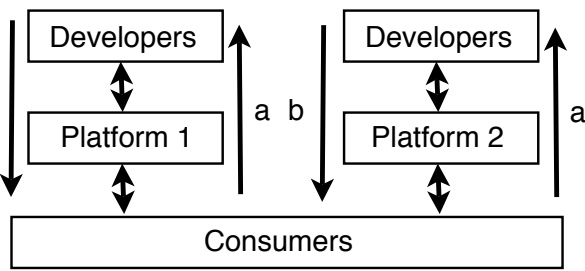

Closed-Open

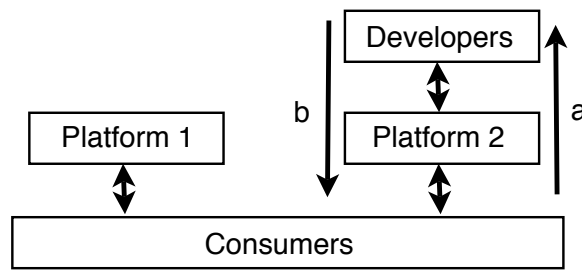

Figure 1: In stage 1 firms choose between providing an open or providing a closed platform. Their choices give rise to these sub-games in stage 2 .

from each platform $k \in\{1,2\}$. The costs of developing applications are sufficiently high to ensure that some developers always stay out of the market. ${ }^{10}$

Parameter $s_{k}$ denotes the fee or subsidy imposed or handed out by the platform. If $s$ is positive, it represents a fee that must be paid for the right to develop an application. An example is a fee that must be paid for an application development kit needed to create the application. If $s$ is negative it is a subsidy. It can then be any type of action by the firm operating the platform that reduces the costs of developing an application, such as training, subsidized conferences and free extensive documentation of interfaces.

\section{$2.3 \quad$ Timing}

- In stage 1, firms simultaneously decide whether to be open or closed. Figure 1 illustrate possible outcomes.

- In stage 2 , firms observe the choice made by the rival. Then, they simultaneously set prices to consumers. Firms providing open platforms also set the fee or subsidy to application developers. Consumers and developers then observe prices and the fees or subsidies. They form rational expectations regarding participation of the opposite group. Then, consumers buy the platform yielding the highest utility and developers decide separately for each platform if they should develop for the platform.

This timing captures the fact that the choice of providing a closed or an open platform is more long term than the choice of prices and fees (subsidies). It

\footnotetext{
${ }^{10}$ The assumptions needed are $f>\frac{a+b}{4}$ when the platforms are open and $f\left(a^{2}+4 a b+b^{2}+\right.$ $3(a+b-4 f) t)<a b(a+b))$ when one platform is open and the other is closed.
} 
allows firms to commit to providing an open or a closed platform before setting prices and fees.

In what follows, I solve this game by backwards induction. I look for pure strategy sub-game perfect Nash equilibria. I start by analyzing pricing in the second stage of the game. I consider separately all four sub-games outlined in figure 1. Then, I move back to the first stage of the game and analyze the choice between providing an open or a closed platform.

\section{Analysis}

\subsection{Stage 2: Closed-Closed}

When both platforms are closed, the setup reduces to the standard Hotelling model with firms at both endpoints of the unit interval. For the consumer who is indifferent between purchasing the platform from firm 1 or firm $2, v-t x_{i}-$ $p_{1}=v-(1-t) x_{i}-p_{2}$ holds. Then, demand for firm 1's platform is equal to $n_{c 1}=\frac{1}{2}+\frac{p_{2}-p_{1}}{2 t}$. Demand for firm 2's platform is equal to $n_{c 2}=1-n_{c 1}$. The firms simultaneously set price to maximize

$$
\pi_{k C C}=p_{k} n_{c k}
$$

This results in equilibrium prices of $p_{k C C}^{*}=t$, and profits of $\pi_{k C C}^{*}=\frac{t}{2}$. The second-order conditions, $-\frac{1}{t}<0$, are satisfied. Prices and profits are decreasing in the intensity of competition between firms.

\subsection{Stage 2: Open-Open}

The consumer who is indifferent between purchasing platform 1 and purchasing platform 2 is now located at the $x_{i}$ that satisfies $v+b n_{a 1}-t x_{i}-p_{1}=v+b n_{a 2}-(1-$ t) $x_{i}-p_{2}$. Demand for firm 1's platform conditional on the number of applications at each platform is then equal to $n_{c 1}^{c o n d}=\frac{1}{2}+\frac{b n_{a 1}-b n_{a 2}}{2 t}+\frac{p_{2}-p_{1}}{2 t}$. Demand for firm 2's platform conditional on the number of applications at each platform is $n_{c 2}^{\text {cond }}=1-n_{c 1}^{\text {cond }}$. The developer who is indifferent between developing and not developing an application for platform $k$ is located at $y_{j}=\frac{a n_{c k}-s_{k}}{f}$. Demand for developing applications for platform $k$ conditional on the number of consumers purchasing each platform is then $n_{a k}^{c o n d}=\frac{a n_{c k}-s_{k}}{f}$. To obtain demands as functions of prices on both sides of the market, I simultaneously solve equations $n_{c 1}=n_{c 1}^{\text {cond }}, n_{c 2}=n_{c 2}^{c o n d}, n_{a 1}=n_{a 1}^{\text {cond }}$ and $n_{a 2}=n_{a 2}^{c o n d}$ to obtain

$$
\begin{aligned}
& n_{c 1}\left(p_{1}, p_{2}, s_{1}, s_{2}\right)=\frac{b\left(s_{2}-a-s_{1}\right)+f\left(p_{2}-p_{1}+t\right)}{2(f t-a b)} \\
& n_{c 2}\left(p_{1}, p_{2}, s_{1}, s_{2}\right)=\frac{b\left(s_{1}-a-s_{2}\right)+f\left(p_{1}-p_{2}+t\right)}{2(f t-a b)} \\
& n_{a 1}\left(p_{1}, p_{2}, s_{1}, s_{2}\right)=\frac{a\left(b\left(s_{1}+s_{2}\right)+f\left(p_{2}-p_{1}+t\right)\right)-a^{2} b-2 f s_{1} t}{2 f(f t-a b)}, \text { and }(7) \\
& n_{a 2}\left(p_{1}, p_{2}, s_{1}, s_{2}\right)=\frac{a\left(b\left(s_{1}+s_{2}\right)+f\left(p_{1}-p_{2}+t\right)\right)-a^{2} b-2 f s_{2} t}{2 f(f t-a b)}
\end{aligned}
$$


Firms simultaneously set prices, $p_{k}$, to consumers and the fees (subsidies) to application developers, $s_{k}$, to maximize

$$
\pi_{k O O}=p_{k} n_{c k}\left(p_{1}, p_{2}, s_{1}, s_{2}\right)+s_{k} n_{a k}\left(p_{1}, p_{2}, s_{1}, s_{2}\right)
$$

Equilibrium prices are

$$
p_{k O O}^{*}=t-\frac{a(a+3 b)}{4 f} \text { and } s_{k O O}^{*}=\frac{a-b}{4},
$$

and platform profits are

$$
\pi_{k O O}^{*}=\frac{t}{2}-\frac{a^{2}+6 a b+b^{2}}{16 f} .
$$

The second-order conditions, $-\frac{f}{f t-a b}<0,-\frac{2 f t-a b}{f(f t-a b)}<0$, and $\frac{8 f t-a^{2}-6 a b-b^{2}}{4(a b-f t)^{2}}>$ 0 are satisfied for $4 f t-(a+b)^{2}>0$.

Firms balance the price to consumers with fees (or subsidies) to application developers so as to best internalize cross-group externalities. Application developers are subsidized if the valuation of applications by consumers is sufficiently large in relation to developers' profits from reaching an additional consumer (if $b>a)$.

As noted by Armstrong (2006), profits from the multi-homing side (the application developer side) are competed away on the single-homing (consumer) side of the market. The reason is that the competition for consumers is intensified when platforms are open. A cut in the price leads to more consumers buying the platform. It also attracts more application developers because more consumers have bought the platform. Both platforms then have strong incentives to cut price. These incentives are increasing in the size of cross-group externalities and decreasing in the costs of developing applications (because it becomes easier to attract developers). Hence, profits (and prices) are increasing in the costs of developing applications and decreasing in the size of the cross-group externalities.

\subsection{Stage 2: Open-Closed and Closed-Open}

Assume that firm 1 has the open platform and firm 2 has the closed platform. The formulas for the reverse case can easily be obtained by renaming the platforms.

Conditional on the number of applications developed for platform 1, the consumer who is indifferent between platforms is located at the $x_{i}$ that satisfies $v+b n_{a 1}-t x_{i}-p_{1}=v-(1-t) x_{i}-p_{2}$. Demand for platform 1 conditional on the number of application developers that develop for platform 1 is $n_{c 1}^{\text {cond }}=\frac{1}{2}+\frac{b n_{a 1}}{2 t}+\frac{p_{2}-p_{1}}{2 t}$. Demand for platform 2 conditional on the number of application developers that develop for platform 1 is $n_{c 2}^{\text {cond }}=1-n_{c 1}^{\text {cond }}$. The developer who is indifferent between developing for platform 1 and not developing is located at $y_{j}=\frac{a n_{c 1}-s_{1}}{f}$. Demand for developing applications for platform 1 conditional on the number of consumers purchasing platform 1 is then $n_{a 1}^{c o n d}=\frac{a n_{c 1}-s_{1}}{f}$. To obtain demands as functions of prices on both sides of the market, I simultaneously solve equations $n_{c 1}=n_{c 1}^{c o n d}, n_{c 2}=n_{c 2}^{c o n d}$ and 


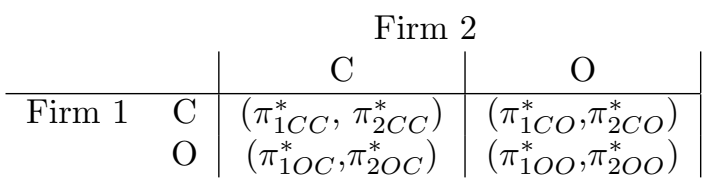

Figure 2: The simultaneous game played in stage 1.

$n_{a 1}=n_{a 1}^{c o n d}$. This gives

$$
\begin{aligned}
n_{c 1}\left(p_{1}, p_{2}, s_{1}\right) & =\frac{b s_{1}+f\left(p_{1}-p_{2}-t\right)}{a b-2 f t}, \\
n_{c 2}\left(p_{1}, p_{2}, s_{1}\right) & =\frac{a b-b s_{1}-f\left(p_{1}-p_{2}+t\right)}{a b-2 f t}, \text { and } \\
n_{a 1}\left(p_{1}, p_{2}, s_{1}\right) & =\frac{a\left(p_{1}-p_{2}-t\right)+2 s_{1} t}{a b-2 f t} .
\end{aligned}
$$

Firm 1 sets the price to consumers and the fee (or subsidy) to application developers to maximize

$$
\pi_{1 O C}=p_{1} n_{c 1}\left(p_{1}, p_{2}, s_{1}\right)+s_{1} n_{a 1}\left(p_{1}, p_{2}, s_{1}\right) .
$$

Firm 2 simultaneously sets the price to consumers to maximize

$$
\pi_{2 O C}=p_{2} n_{c 2}\left(p_{1}, p_{2}, s_{1}\right) .
$$

Equilibrium prices are

$$
\begin{aligned}
& p_{1}^{*}=\frac{(4 f t-a(a+b))(3 f t-a b)}{f\left(12 f t-a^{2}-4 a b-b^{2}\right)}, \\
& s_{1}^{*}=\frac{(a-b)(3 f t-a b)}{12 f t-a^{2}-4 a b-b^{2}}, \text { and } \\
& p_{2}^{*}=\frac{\left(6 f t-(a+b)^{2}\right)(2 f t-a b)}{f\left(12 f t-a^{2}-4 a b-b^{2}\right)} .
\end{aligned}
$$

Platform profits are

$$
\begin{aligned}
& \pi_{1 O C}^{*}=\frac{\left(8 f t-(a+b)^{2}\right)(a b-3 f t)^{2}}{f\left(a^{2}+4 a b+b^{2}-12 f t\right)^{2}}, \text { and } \\
& \pi_{2 O C}^{*}=\frac{\left((a+b)^{2}-6 f t\right)^{2}(2 f t-a b)}{f\left(a^{2}+4 a b+b^{2}-12 f t\right)^{2}} .
\end{aligned}
$$

The second-order conditions $-\frac{2 f}{2 f t-a b}<0,-\frac{4 t}{2 f t-a b}<0$ and $\frac{8 f t-(a+b)^{2}}{(a b-2 f t)^{2}}>0$ are satisfied for $4 f t-(a+b)^{2}>0$. By reversing the identities of the platforms, we can get profits under the outcome Closed-Open. These profits are $\pi_{1 C O}^{*}=\pi_{2 O C}^{*}$ and $\pi_{2 C O}^{*}=\pi_{1 O C}^{*}$. Application developers are subsidized if $b>a$. The size of cross-group externalities and the costs of developing applications can either increase or decrease profits. The reason is that while cross-group externalities benefit the platform, they also lead to intensified competition for consumers. 


\subsection{Stage 1: Open or Closed?}

The firms simultaneously decide if third-parties should be able to develop for their platform. The game played in stage 1 is summarized in figure 2. By solving the first stage, we can obtain the following proposition.

Proposition 1. For sufficiently large differences in cross-group externalities, both firms provide open platforms. They are trapped in a prisoner's dilemma. If the difference in cross-group externalities is sufficiently small, both firms provide closed platforms. For intermediate differences in cross-group externalities, one platform is open and one is closed.

Proof. First, assume that it is desirable for firm 1 to offer an open platform if firm 2 offers a closed platform. Then $\pi_{1 O C}^{*}>\pi_{1 C C}^{*}$ or $\frac{\left(8 f t-(a+b)^{2}\right)(a b-3 f t)^{2}}{f\left(a^{2}+4 a b+b^{2}-12 f t\right)^{2}}>$ $\frac{t}{2}$. Simplifying, using $4 f t-(a+b)^{2}>0$, leads to the following condition $2 a^{2} b^{2}+\left(a^{2}-6 a b+b^{2}\right) f t>0$. Note that this condition holds if $a^{2}-6 a b+b^{2}>0$ or equivalently, if $(a-b)^{2}-4 a b>0$ (there is a sufficient difference in crossgroup externalities). Assuming that $a^{2}-6 a b+b^{2}>0$, it is possible to show that $\pi_{1 O O}^{*}>\pi_{1 C O}^{*}$ or that $\frac{8 f t-a^{2}-6 a b-b^{2}}{16 f}>\frac{\left((a+b)^{2}-6 f t\right)^{2}(2 f t-a b)}{f\left(a^{2}+4 a b+b^{2}-12 f t\right)^{2}}$. Then firm 1 has a dominant strategy to open the platform. This also holds for firm 2. Hence, the pure strategy Nash equilibrium is for both firms to provide open platforms. The equilibrium is shown in area 1 in figure 3 . Since $a^{2}+6 a b+b^{2}>0$, it must be that $\pi_{1 C C}^{*}>\pi_{1 O O}^{*}$ and the game is a prisoner's dilemma.

Second, now suppose that $2 a^{2} b^{2}+\left(a^{2}-6 a b+b^{2}\right) f t>0$, but that $a^{2}-$ $6 a b+b^{2}<0$ (so $f t$ is small). Then $\pi_{1 O C}^{*}>\pi_{1 C C}^{*}$, but it need not be that $\pi_{1 O O}^{*}>\pi_{1 C O}^{*}$. If, instead, $\pi_{1 O O}^{*}<\pi_{1 C O}^{*}$, the game has two pure strategy Nash equilibria. Either firm 1 provides an open platform and firm 2 provides a closed platform or the reverse holds. Equilibria of this type must lie in area 3 in figure 3 , but area 3 also contains parameter combinations resulting in an equilibrium characterized by both platforms being open.

Third, now assume that it is desirable for firm 1 to provide a closed platform if firm 2 provides a closed platform. Then, $2 a^{2} b^{2}+\left(a^{2}-6 a b+b^{2}\right) f t<0$ and it is possible to use this to show that $\pi_{1 C O}^{*}>\pi_{1 O O}^{*}$. Firm 1 has a dominant strategy to remain closed. This also holds for firm 2 and the pure strategy Nash equilibrium is for both firms to provide closed platforms. This equilibrium is characterized by parameter combinations in area 2 in figure 3 .

The proposition highlights that firms may have a dominant strategy to remain closed, despite the fact that opening the platform is free and consumers value an open platform more highly than a closed platform. The reason is that competition is intensified when platforms are open. All else equal, a given price cut to consumers when platforms are open attracts more new consumers as compared to when platforms are closed because the price is lower and the platform value higher.

To see this formally, we can examine the best response functions of firm 1 . The best response functions for price for firm 1 when its platform is closed are

$$
\begin{aligned}
p_{1}\left(p_{2}\right)_{C C} & =\frac{t+p_{2}}{2}, \text { and } \\
p_{1}\left(p_{2}, s_{2}\right)_{C O} & =\frac{t+p_{2}}{2}-\frac{b\left(a-s_{2}\right)}{2 f} .
\end{aligned}
$$




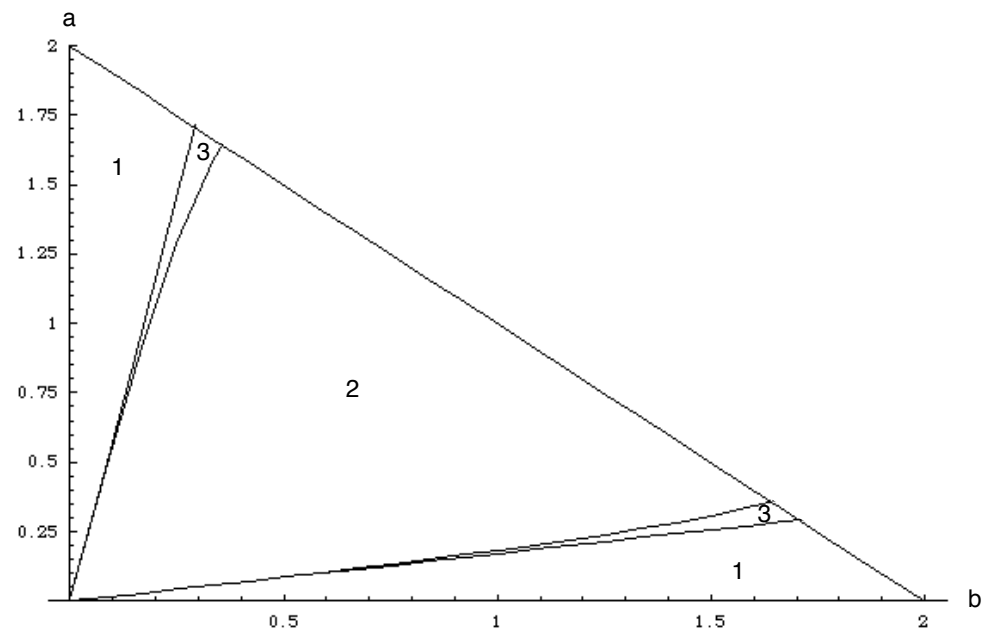

Figure 3: Equilibrium regions for $f=t=1$. The line from $(0,2)$ to $(2,0)$ corresponds to $4 f t-(a+b)^{2}=0$, the line separating areas 1 and 3 to $(a-b)^{2}-$ $4 a b=0$ and the line separating areas 2 and 3 to the equation $2 a^{2} b^{2}+\left(a^{2}-\right.$ $\left.6 a b+b^{2}\right) f t=0$. Varying $f$ or $t$ scales the picture.

When firm 1 provides an open platform, the best response functions are

$$
\begin{aligned}
p_{1}\left(s_{1}, p_{2}\right)_{O C} & =\frac{t+p_{2}}{2}-\frac{(a+b) s_{1}}{2 f}, \text { and } \\
p_{1}\left(s_{1}, p_{2}, s_{2}\right)_{O O} & =\frac{t+p_{2}}{2}-\frac{(a+b) s_{1}}{2 f}-\frac{b\left(a-s_{2}\right)}{2 f} .
\end{aligned}
$$

Studying these, we can see that because $\frac{b\left(a-s_{2}\right)}{2 f}>0$ in equilibrium, firm 1 has incentives to price more aggressively if firm 2 provides an open platform. ${ }^{11}$ Hence, by committing to providing closed platforms, firms are able to reduce the intensity of competition for consumers.

In equilibrium, the effect on profits from opening the platform depends on a balance between a) benefits from an increase in the value of the platform and the possibility to profit from application developers and b) intensified competition for consumers. ${ }^{12}$

For $a$ sufficiently similar to $b$, both firms have individual incentives to provide a closed platform. An open platform would lead to lower profits due to intense competition for consumers. This case is represented in area 2 in figure 3 . If

\footnotetext{
${ }^{11}$ Firm 1 is either more or less aggressive in pricing when open. If $b>a$, so that $s_{1}<0$ in equilibrium, firm 1 is less aggressive in pricing. If $b<a$, so $s_{1}>0$ in equilibrium, firm 1 is more aggressive in pricing.

${ }^{12}$ There is a difference between a standard quality increase of the platform and a quality increase induced by more application developers developing for the platform. The size of a standard quality increase does not depend on price, whereas the quality increase due to more application developers depends on prices on both sides of the market. Further, the total profits of the platform are the sum of profits from consumers and profits from application developers, so that increases in quality brought about by through having more application developers have a different effect on profits than standard quality increases.
} 
$a$ is much larger than $b$, acquiring additional consumers is very profitable for the firm as the fee for the right to develop applications can be substantially increased. Even though competition for consumers is intensified with an open platform, the firm finds it profitable to open the platform because selling the rights to develop applications recoups losses from intensified competition for consumers.

If $b$ is much larger than $a$, the ability to subsidize application developers so as to increase the value of the platform for consumers makes it profitable to provide an open platform. The value increase in the platform becomes sufficiently large so as to compensate for the effect of intensified competition. These two cases are represented by area 1 in figure 3 . In both cases, the firms are trapped in a prisoner's dilemma. They would have been better off had they been able to collude in stage 1 on keeping the platforms closed.

For intermediate differences in $a$ and $b$, it may be that platforms prefer to be open if the rival is closed and closed if the rival is open. In these cases profit increases from being open are enough to compensate for intensified competition only if the rival is closed, not if it is open. The reason is that competition is more intense when both firms are open than if only one firm is open. Area 3 in figure 3 contains such parameter combinations, but area 3 also contains parameter combinations where the equilibrium is for both firms to provide open platforms.

Finally, application development costs $(f)$ and the intensity of competition between platforms $(t)$ also affect the choice of providing an open versus a closed platform. Increased development costs for applications and decreases in the intensity of competition (increases in $t$ ) tend to make a closed platform more likely due to diminished benefits from cross-group externalities. This can be seen by noting that if $f t$ is large and the difference in cross-group externalities small, it is more likely that $\pi_{1 O C}^{*}<\pi_{1 C C}^{*}$ and $\pi_{1 C O}^{*}>\pi_{1 O O}^{*}$ since it is more likely that $2 a^{2} b^{2}+\left(a^{2}-6 a b+b^{2}\right) f t<0$.

\section{Conclusion}

Why are some platforms open to third-party development while others are closed? In this paper, I take a two-sided market approach and highlight that opening the platform to third-party development both leads to an increase in the value of the platform and to intensified competition for consumers. Hence, firms might prefer to commit to keeping their platforms closed despite the fact that opening the platform is costless and open platforms are more valuable to consumers.

In a two-stage model of a two-sided market, I find three types of equilibrium configurations. Both platforms are open (and the firms are trapped in a prisoner's dilemma), both platforms are closed, or one platform is open and one is closed. The outcome depends on the relative difference in cross-group externalities, the intensity of competition for consumers and the cost for developing applications.

This stylized model can be extended in several directions. First, I have not discussed policy and social welfare in markets where platforms can choose between being open or closed. For such a discussion, see Tåg (2008). Second, it was assumed that the market was completely covered on the consumer side. This 
implies that price cuts to consumers by the firms do not attract new customers. Neither do increases in quality from allowing third-party application development. Maintaining the assumption of a covered market thus biases the results in favor of closed platforms. However, the assumption does not change the fact that competition between open platforms is more intense than competition between closed platforms. Hence, the trade-off between intensified competition and a higher quality platform still remains.

Third, the current setup does not allow the firms to choose between in-house application development and outsourcing the development of applications to third-parties. I only consider the choice between allowing third-party application development or not. This is likely to bias the results in favor of open platforms, as opening the platform is the only way to increase the quality of the platform in the current model.

Fourth, it was assumed that third-party application developers had to incur the fixed cost of developing an application once for each platform. Once an application has been developed, however, it is likely that porting it to another platform is less expensive than rewriting it completely. Introducing this aspect into the model potentially significantly complicates the analysis. The reason is that in the current set up, each application developer decides on developing for one platform independently of her decision to develop for the other. As a consequence, the firms only compete directly for users and not for application developers, as the choice to develop for one is independent of the choice to develop for the other. If the costs for developing an application are conditional on whether the application was previously been developed, development choice becomes interdependent. The likely bias of this extension on the results is not clear and hence, is a good direction for future research.

Fifth, I have cast the model in the framework of software and hardware platforms. It could also apply to other two-sided markets where choosing between providing a one-sided or a two-sided platform is possible. In particular, the analysis could be adapted to study how magazines and TV stations are funded (see Kind, Nilssen, and Sorgard (2005)). A "closed" platform in this framework is a magazine or TV station without advertisements. An "open" platform has advertisements and is hence two-sided.

\section{References}

Armstrong, M. (2006). Competition in two-sided markets. RAND Journal of Economics 37, 668-691.

Arora, A. and F. Bokhari (2007). Open versus closed firms and the dynamics of industry evolution. Journal of Industrial Economics 55, 499-527.

Borenstein, S. and J. MacKie-Mason (2000). Exercising market power in proprietary aftermarkets. Journal of Economics and Management Strategy 9, $157-188$.

Caillaud, B. and B. Jullien (2003). Chicken and egg: Competition among intermediation service providers. RAND Journal of Economics 34, 309-328.

Choi, J. P. (2006). Tying in two-sided markets with multi-homing. NET Institute Working Paper 06-04. 
Church, J. and N. Gandal (2000). Systems competition, vertical merger, and foreclosure. Journal of Economics and Management Strategy 9, 25-51.

Economides, N. (1989). Desireability of compatibility in the absence of network externalities. American Economic Review 79, 1165-1181.

Hagiu, A. (2006). Pricing and commitment by two-sided platform. RAND Journal of Economics 37, 720-737.

Hagiu, A. (2007a). Merchant or two-sided platform? Review of Network Economics 6, 115-133.

Hagiu, A. (2007b). Proprietary vs. open two-sided platforms and social efficiency. HBS Working Paper 0\%-095.

Hagiu, A. and R. Lee (2007). Exclusivity and control. HBS Working Paper 08009

Kende, M. (1998). Profitability under an open versus a closed system. Journal of Economics and Management Strategy 7, 307-326.

Kind, H. J., T. Nilssen, and L. Sorgard (2005). Financing of media firms: Does competition matter? Centre for Industrial Economics Discussion Paper 2005-08.

Lee, R. (2007). Vertical integration and exclusivity in platform and two-sided markets. NET Institute Working Paper 07-39.

Matutes, C. and P. Regibeau (1988). Mix and match: Product compatibility without network externalities. RAND Journal of Economics 19, 221-234.

Rochet, J.-C. and J. Tirole (2003). Platform competition in two-sided markets. Journal of the European Economic Association 1, 990-1029.

Rochet, J.-C. and J. Tirole (2006). Two-sided markets: A progress report. RAND Journal of Economics 35, 645-667.

Schiff, A. (2003). Open and closed systems of two-sided networks. Information Economics and Policy 15, 425-442.

Shapiro, C. (1995). Aftermarkets and consumer welfare: Making sense of kodak. Antitrust Law Journal 63, 483-511.

Tåg, J. (2008). Efficiency and the provision of open platforms. IFN Working Paper 748. 